\title{
Preface of "The Third Symposium on Mathematical Methods in Economics and Nature Use"
}

\author{
Alexander N. Medvedeva) and Marina A. Medvedeva ${ }^{\text {b) }}$ \\ ${ }^{1}$ Department of Systems Analysis and Decision Making, Ural Federal University, Mira 19, Yekaterinburg, Russia, \\ 620002 \\ a)Corresponding author: alnikmed52@gmail.com \\ b)marmed55@yandex.ru
}

"The Third Symposium on Computational Methods in Economics and Nature Use" is dedicated to the discussion of development and practical application of computational methods and information technologies in such important spheres of human activity as economics, nature use, and related fields.

The presentations of representatives of academic and university science, as well as doctoral and master students were presented at the Symposium in oral and poster format.

The Symposium program included 25 presentations, which addressed newly created models and methods, as well as particular examples of their use for the evaluation, analysis and forecasting of different indicators in the field of economics, nature use, management, and related spheres.

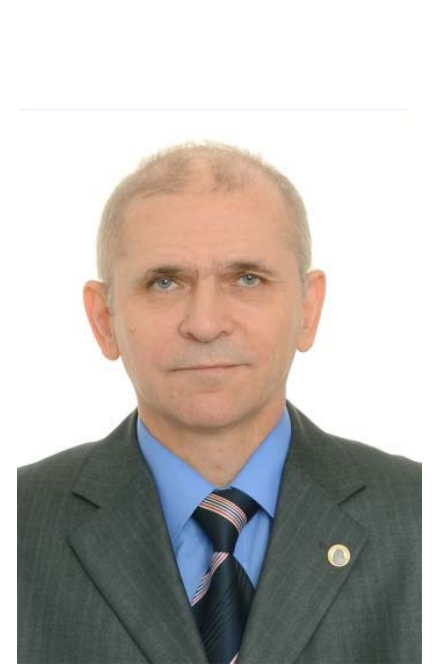

\section{Alexander N. Medvedev}

Assoc. Prof. Dr. Alexander N. Medvedev works as a Scientific Secretary and a Leading Researcher of the Institute of Industrial Ecology of the Ural Branch of the Russian Academy of Sciences and as an Associate Professor (part time) of Department of Systems Analysis and Decision Making of Ural Federal University, Yekaterinburg, Russia.

He got his PhD in Technical Sciences at the Institute of Geophysics UB RAS, in 1990, under the supervision of Professor Valeriy V. Kormiltsev. His main scientific interests are in the field of application of computer modeling and experimental studies for solving the tasks in the sphere of nature use and environmental protection.

He participated in several International Conferences on Applied Mathematics and Geosciences (ICNAAM 2015-2019, Rhodes, Thessaloniki, Greece; ICCMSE 20172019, Rhodes, Thessaloniki, Greece; ICAMCS 2017, Rome, Italy; CAO 2015, Garmisch-Partenkirchen, Germany; AMEE 2015-2016, 2018, 2019 Sozopol, Bulgaria; SGEM 2014-2016, 2019, Albena, Bulgaria, etc.).

He organized 6 Mini Symposiums in the frames of ICCMSE and ICNAAM 2017-2019.

$\mathrm{He}$ is an author of more than 140 scientific articles and about 10 textbooks.

Alexander Medvedev is an Active Member of the European Academy of Natural Sciences (Hanover, Germany), Federal Expert on Nature Use (Moscow, Russia), and evaluator of international scientific-technical projects of the European Union (European and International Cooperation Projects Management Agency, Bonn, Germany). 


\section{Marina A. Medvedeva}

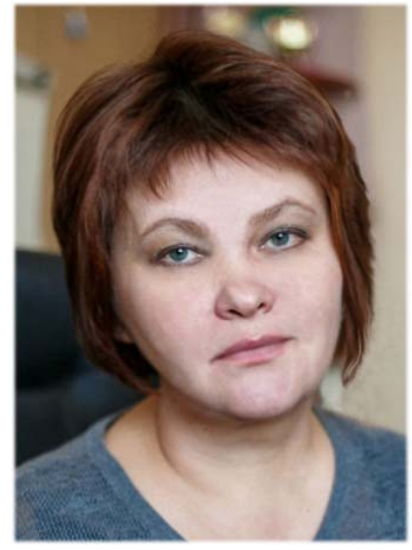

Assoc. Prof. Dr. Marina A. Medvedeva works as a Head of Department of Systems Analysis and Decision Making and Associate Professor of Ural Federal University, Yekaterinburg, Russia.

She got his PhD in Physics and Mathematics at the Institute of Industrial Ecology UB RAS in 2005, under the supervision of Professor Oleg I. Nikonov. Her main scientific interests are in the field of application of computer modeling and information technologies in economics, business, and education.

She was a participant of several International Conferences on Applied Mathematics and Informatics (ICNAAM 2009-2019, Greece; ICCMSE 2017-2019, Rhodes, Thessaloniki, Greece; CAO 2012, Rimini, Italy, CAO 2018, Yekaterinburg, Russia; MSCI 2015, Sliema, Malta; AMEE 2015-2016, Sozopol, Bulgaria; SGEM 2014-2016, Albena, Bulgaria, etc.).

She organized 6 Mini Symposiums in the frames of ICCMSE and ICNAAM 2017-2019.

She is an author of more than 110 scientific articles and about 11 textbooks.

Marina A. Medvedeva is a leader of the international master educational program on Business Informatics in Ural Federal University, Yekaterinburg, Russia. 